\title{
Mercury or Mercury Free Restorations in Oral Cavity
}

\author{
Rakesh Kumar Yadav ${ }^{1}$, Umesh Pratap Verma ${ }^{2}$, Rini Tiwari ${ }^{3}$, Akhilanand Chaurasia ${ }^{4}$ \\ ${ }^{1,3}$ Department of Conservative Dentistry and Endodontics, King George's Medical University, Lucknow, India \\ ${ }^{2}$ Department of Periodontology, King George's Medical University, Lucknow, India \\ ${ }^{4}$ Department of Oral Medicine and Radiology, King George's Medical University, Lucknow, India
}

\begin{tabular}{l} 
Article Info \\
\hline Article history: \\
Received Jun 10, 2018 \\
Revised Sep 10, 2018 \\
Accepted Sep 19, 2018 \\
\hline
\end{tabular}

\section{Keyword:}

Dental amalgam

Mercury amalgams

Mercury free amalgams

\begin{abstract}
Amalgam is basically a concoction of metals that has been used as a potent filling material in dentistry for the last 150 years. Amalgam usually consists of silver, mercury, tin and copper. Dental amalgam is a material used to fill cavities of tooth. Over the years, amalgam has become a topic of concern because it contains mercury. Mercury is a naturally occurring metal in the environment. Mercury exists as a liquid in room temperature but when heated, it becomes a gas. Flexibility of amalgam as a filling material is due Mercury. An alloy powder, a compound that is soft in nature when mixed with mercury makes it enough to mix and condense into the tooth. It hardens quickly and offers strong resistance to the forces of biting and chewing. There are studies reported on the safety of amalgam fillings. In 2005, European Union launched a comprehensive mercury strategy to reduce use of mercury. In 2008, countries like Norway and Denmark restricted the use of dental amalgam containing mercury. In 2009, this research was evaluated by U.S. Food and Drug Administration (FDA) and found no rationale to limit the use of amalgam. There are certain restorative materials that are available commercially that are mercury free in nature like Gold, Porcelain, Gallium alloys, Composite resin restoratives etc. They offer many advantages over amalgams containing mercury like: seals the dentin from future decay, reinforces remaining tooth structure, provides smooth and bonded margins, conservative and it blends naturally.
\end{abstract}

Copyright (C) 2018 Institute of Advanced Engineering and Science. All rights reserved.

\section{Corresponding Author:}

Rakesh Kumar Yadav,

Department of Conservative Dentistry and Endodontics,

King George's Medical University,

Lucknow, Uttar Pradesh, 226003, India.

Email: rakeshanita10@yahoo.in

\section{INTRODUCTION}

Tooth decay or dental caries have been considered as a major health problem globally [1]. It is an oral disease that affects $60-90 \%$ of world population of children and adults. Presently, the status of dental caries varies in different parts of the world. In the treatment of dental caries, infected tissue is removed and the tooth is restored with a restorative material. The mostly used material for filling is dental amalgam which is durable and less expensive and has been used for more than a decade in different countries [2-5].

Dental amalgam contains mercury, tin, copper, zinc, silver and other trace elements. Dental amalgam contains $50 \%$ mercury of its total mass. As dental amalgam is cost effective it has been used by many practitioners for treatment of restoration of tooth and many oral diseases. Table 1 shows advantages and disadvantages of using dental amalgam. A study reported by Mackert and Wahl in 2004 [6] showed that more than $75 \%$ of dentists in The USA used dental amalgams for restorations of the cavities. A study conducted by Berthold, 2002 [7] showed that Class I and Class II defects of teeth in the USA were treated by Dental amalgam restorations. According to American Dental Association (ADA, 2002) [8] in the USA more than 70 million dental amalgam restorations has been applied. Various countries use dental amalgam is as a 
recuperative material; however its imprudent handling may lead to health risks of humans especially the workers who deal with mercury emission in some or the other forms and also detrimental effect on the environment due to mercury exposure [9].

Table 1. Advantages and Disadvantages of Dental amalgam

\begin{tabular}{llll}
\hline \multicolumn{1}{c}{ Advantages } & & \multicolumn{2}{c}{ Disadvantages } \\
\hline 1. & Economical & 1. & Poor aesthetic qualities \\
2. & Long term clinical performance & 2. & Mercury toxicity, a major concern \\
3. & Durability & 3. & Corrosion \\
4. & Can be manipulated easily & 4. & Allergic sometimes \\
5. & Can be easily repaired or replaced & 5. & Marginal breakdown \\
6. & Required less placement time compared to others & & \\
\hline
\end{tabular}

\section{TOXICOLOGY OF MERCURY RELEASED FROM DENTAL AMALGAM}

Although dental amalgam, as restoration material has many advantages but due to the presence of mercury in it, it has become a topic of study since many years. Other than gallium, mercury is the solely metal that is in fluid state at room temperature [16]. There are various means of exposure of mercury to general public like air, water, food item and dental restorations is most common one. Mercury discharged from the dental amalgam is typically in the vapor frame. Several studies showed that mercury vapours were found in the exhaled breath tested by using a bronchoscope placed in the trachea [17] and in the oral cavity with mouth open or closed [18] of humans. These studies revealed that mercury in the form of vapours is released from the dental restorations. The release rate of mercury vapours may vary person to person and factors like eating habits, age, area, amount of amalgam placed to cover the cavity etc. Lorscheider et al [19], in 1995 reported that the individuals who were not occupationally presented to mercury but rather still were found to have mercury content was because of the dental amalgam reclamation around then.

Excessive chewing or brushing with the teeth exposed with dental amalgam restorations can change the preventive properties of the oxide layers present on the tooth surface and hence can accelerate the rate of elementary mercury [17] as well as inorganic mercury as oxidative products [20]. A study that described the levels of mercury in urinary and scalp hair of New England Children's Amalgam Trial (NECAT) participants of age 6-10 years and compared with those who were not exposed to mercury. The study period was 5 years. The mean Hg levels of scalp was approx. $0.5 \mathrm{mg} / \mathrm{g}$ out of which $17-29 \%$ of children had $\geq 0.5 \mathrm{mg} / \mathrm{g}$ scalp mercury level while $5-8.5 \%$ children had $\geq 1 \mathrm{mg} / \mathrm{g}$ in given time period. In adjusted models high scalp mercury levels was due to high fish consumption. The urinary mercury levels varied over two years that ranged between 0.7 and aprrox $1.0 \mathrm{mg} / \mathrm{g}$ creatinine. The adjusted model those who had amalgam restoration showed a significant relationship with urinary mercury levels and was not associated with neuropsychological effects [21].

Al-Saleh et al. in 2011[22], examined mercury levels in 182 children of age between 5-15 years in Saudi Arabia. They measured the mercury levels in urine, toenails and hair of children by atomic absorbtion spectroscopy. The result showed significantly higher mercury level in urinary samples of children having amalgam filling ( $\mathrm{n}=106)$ with mean of $3.763 \mu \mathrm{g} / \mathrm{g}$ creatinine and $3.457 \mu \mathrm{g} / \mathrm{g}$ creatinine in children without amalgam filling. Similar results were obtained for hair samples $0.614 \mu \mathrm{g} / \mathrm{g}(\mathrm{N}=97)$ for children with amalgam filling and $0.242 \mu \mathrm{g} / \mathrm{g}(\mathrm{N}=74)$ for without amalgam fillings. They concluded that mercury exposure may lead to oral health problems like white patches, aphtous ulcers etc.

Similar study was reported in the year 2007 by Zolfaghari et al, [23] assessed the occupational and environmental vulnerability of mercury in hair and nail samples of Iranian Dentists in Tehran. Along with the samples they included a structured questionnaire about exposure of mercury in different areas. The result showed $2.84 \pm 0.47$ and $3.56 \pm 0.53 \mathrm{mg} / \mathrm{kg}$ dry weight of hair and nails respectively while fo the control group was $0.61 \pm 0.07 \mathrm{mg} / \mathrm{kg}$ in hair and $0.39 \pm 0.06 \mathrm{mg} / \mathrm{kg}$ in nails. They concluded that $22 \%$ of dentists had higher level of mercury in hair and surpassed the threshold estimation of $5 \mathrm{mg} / \mathrm{kg}$. A study based on 2001 to 2004 statistics in America revealed that around 180 million people of America have 1.46 millions of amalgam restorations. The result showed 67.2 million Americans exceeded the mercury level $0.3 \mu \mathrm{g} / \mathrm{m} 3$ established by the USEPA [9]. Table 2 explains the diseases and organ dysfunction that occur due to the exposure of mercury vapours from amalgam. 
Table 2. Organ Dysfunction due to Release of Mercury Vapors from Dental Amalgam

\begin{tabular}{|c|c|}
\hline Organ Dysfunction & Conclusion \\
\hline Kidney dysfunction & $\begin{array}{l}\text { Mercury urine level was higher in subjects with dental amalgam filling contrasted with without } \\
\text { amalgam filling subjects. The results were statistically significant. Hence dental amalgams are } \\
\text { responsible for mercury exposure but in dose- dependent fashion [24]. } \\
\text { A } 5 \text { year study showed a significantly higher level of mercury in subjects who had amalgam } \\
\text { restorations contrasted with those who had composite resin restorations. But there was no } \\
\text { statistically difference between neuropsychologic or renal function groups [25]. } \\
\text { The result showed a very slight difference between the subjects with and without dental } \\
\text { restorations; hence amalgam is not responsible for mercury exposure [26]. }\end{array}$ \\
\hline Mercury and healing loss & $\begin{array}{l}\text { Rothwell and Boyd, } 2008 \text { [27] demonstrated a connection between more amalgam fillings, poor } \\
\text { edge at higher frequencies which can prompt presbyacusis in created nations. This closes with the } \\
\text { eliminating of amalgam and accessibility of a superior option. }\end{array}$ \\
\hline Mercury and Kawasaki's & Some case reports reported that mercury play a significant role in Kawasaki's Disease. \\
\hline Disease & $\begin{array}{l}\text { Acrodynia is condition caused in children that is caused by mercury exposure. The symptoms for } \\
\text { this condition are similar to those of Kawasaki's Disease [28]. }\end{array}$ \\
\hline Mercury and & There is an independent relationship between level of mercury in human body and humans \\
\hline Cardiovascular Disease & $\begin{array}{l}\text { having coronary disease. Mercury sometimes may stimulate atherosclerosis which may elevate } \\
\text { the risk of heart diseases. Mercury is responsible for the higher production of free radicals which } \\
\text { binds to the enzyme's sulfhydryl group hence forming a complex with selenium which in turn } \\
\text { increases the lipid peroxidation and increase lipid concentration in blood [29] which may lead to } \\
\text { myocardial infarction and hypertension [30]. }\end{array}$ \\
\hline Mercury and Infertility & $\begin{array}{l}\text { An examination uncovered female dental aide who were presented to dental amalgam had higher } \\
\text { fruitlessness rate [13]. Ladies who had amalgam filling were found to have mercury in urine and } \\
\text { a higher danger of fruitlessness [31]. Even male showed higher risk of infertility due mercury } \\
\text { exposure [32]. Scientific Committee on Emerging and Newly Identified Health Risks has } \\
\text { expressed that there is no verification of barrenness of male and female because of mercury } \\
\text { exposure [33]. }\end{array}$ \\
\hline
\end{tabular}

Government panels, Scientists or Different organization that showed Amalgam fillings are not safe [34] these include: A scientific panel of WHO concluded that there is not any safety level of mercury exposure or any threshold limit below which exposure effects of mercury are not estimated. Federal department of Health, Germany, in 1987 publicized a warning that stated amalgam filling in pregnant women should not be used. Countries like Great Britain, Austria, Sweden, France, Canada, Japan, New Zealand and Australia issued similar statements or even banned the use of amalgam filling. A Norwegian and Swedish National Mercury Amalgam Review panel stated that from safety point of view mercury in amalgam is toxic and should not be used as filling material in teeth. Both countries planned to phase out Dental amalgam. Caulk Inc. it is a company that produces dental amalgam, advised countries that do not use amalgam as a base for making crowns and degenerate root fillings. Swedish medical panel unitedly asked government to stop the use of dental amalgam as a restoration material. The US EPA reported that amalgam filling that are removed and disposed is a hazardous waste and should be sealed. The legislature of state California passed a law that states that all the dentists have to discuss all the detrimental effects of amalgam filling with the patients' prior treatment and mention a warning regarding this on the wall of their office. They also stated that filling material may be responsible for the reproductive harm or defects in child birth. Several European countries have banned the use of amalgam fillings for children and women who are pregnant or have age of having a child. Director of US Federal program advises not to use amalgam for new fillings.

\section{MERCURY FREE RESTORATIONS}

Metal free restorations are the fillings that do not contain mercury and provides a natural appearance to the tooth. They are basically made up of ceramics, composites resins that have color similar to that of tooth. Porcelain resins have exact color of tooth and hide the filling making a tooth look natural without any filling. Mercury free fillings have durable property and are strong enough to bear the pressure of biting and chewing. These restorations protect the teeth and make it strong. They also reduce the level of future decay. Dental amalgam sometime may have leakage because it may shrink that may create spaces in the cavity of the tooth which may lead to bacterial infection. According to American Academy of dentistry states that Dental amalgam is safe and can be used for restoration but many studies have reported the adverse effects of it. Replacement of dental amalgam to composites removes the risk of mercury exposure to human health from amalgams. Table 3 includes different types of mercury free restorative materials with their advantages and disadvantages. 
Table 3. Advantages and Disadvantages of Restorative Materials Other than Amalgam

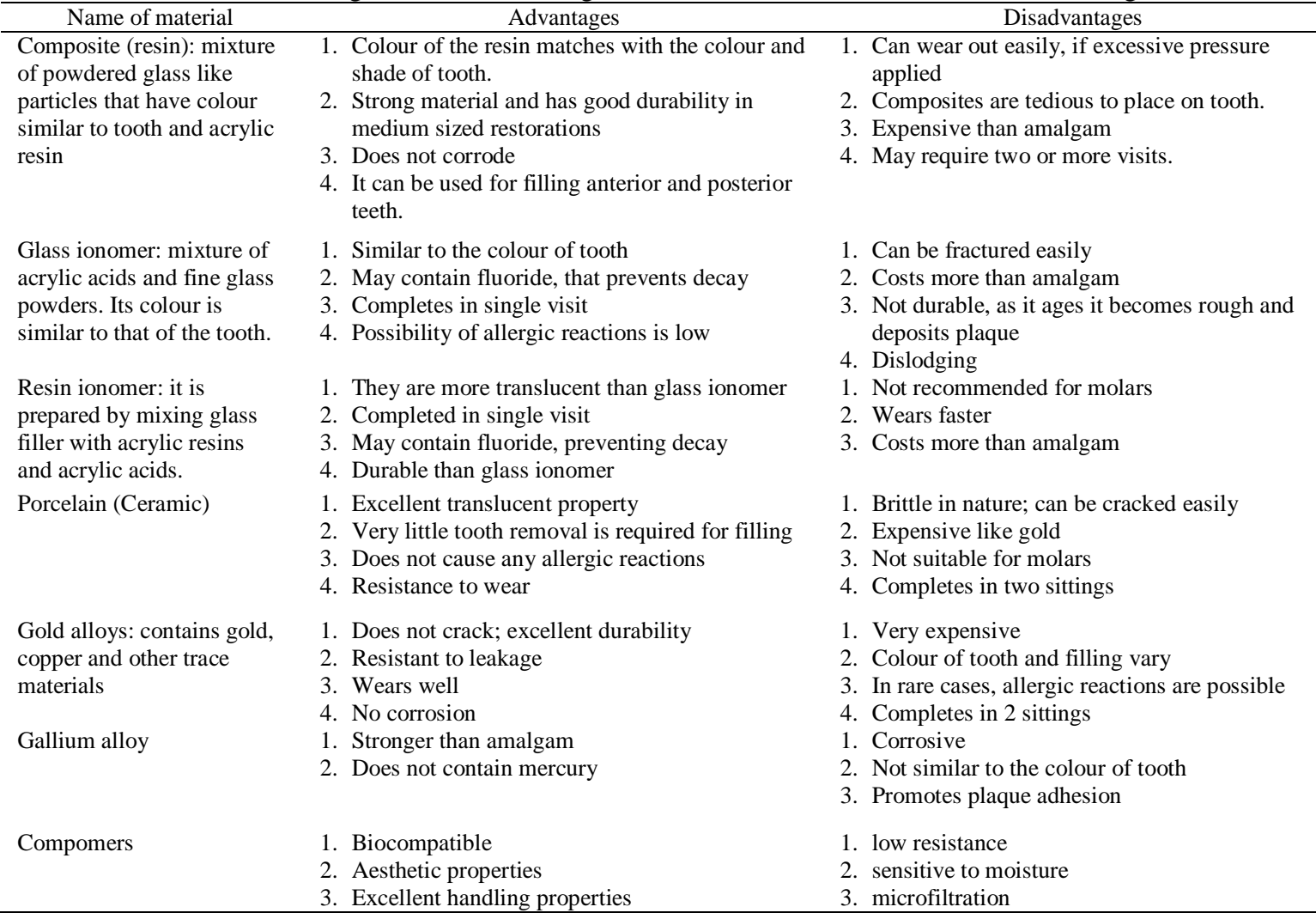

\section{TECHNICAL ADVANTAGES OF RESTORATIVE MATERIALS OTHER THAN AMALGAM}

Mercury free restorations do not damage the healthy tissue and minimally remove the tooth while filling. According to WHO, materials like composite do not destruct the tooth and hence provides longer survival rate to the filling. WHO also emphasized on the survival of tooth rather than survival of filling [1]. Although mercury free materials are not superior in durability with amalgam but still are comparable. WHO suggested that resin composites are equally durable as amalgam [1], [35] conducted a study to compare the longevity of amalgam and composites for a period of 10 years and found that survival rate of composite was $91.7 \%$ and for amalgam it was $89.6 \%$ at 5 years while after 10 years it was $82.2 \%$ and $79.2 \%$ for composite and amalgam respectively. Atraumatic restorative treatment (ART) is technique that uses glass ionomer fillings for restorations. A study [36] in South Africa reported that time taken to restore one amalgam and one composite was $22 \mathrm{~min}$ while with ART technique it was $19.8 \mathrm{~min}$. Fluorides have the capability to prevent caries in teeth. Glass ionomers release fluorides over time. A statically significant study showed that only $2 \%$ secondary caries were observed in restorations with glass ionomers while $10 \%$ caries were observed in restorations with amalgam [37]. During initial placement of composite it not only saves the tooth structure but it permits localized repairs. This saves the tooth as well as money. Opdam et al, 2010, [38] reported that repair rate of composite is better than amalgam restorations. The annual failure rate after 4 years for amalgam was $9.3 \%$ while for composite it was $5.7 \%$. Materials are safer than amalgam: Certain countries have phased out dental amalgam because it contains mercury which neurotoxic in nature and promote mercury free restoration materials. A study showed a direct association of mercury exposure in pregnant ladies due to dental amalgam fillings. Blood samples from the umbilical cord showed high level of mercury in the females who were pregnant [39]. European Commission Scientific Committee on Health and Environmental Risks (SCHER) stated that these materials do not contain mercury so their disposal shows minimal risk to the environment and human health.

\section{CONCLUSION}

Although there is a vast publication of literature regarding toxicological effects of mercury and its alternative mercury free restoration materials. This review does not include all the research work but some portion of literature on the subject of amalgam toxic effects and mercury free filling materials. It appears to 
be clear that, despite of many well defined studies still there is no conclusive proof that amalgam fillings are toxic and not safe for humans. Release of mercury vapors from amalgams may leads to the high level of mercury content in body fluids of dentists/attendants exceeding threshold limit given by WHO. Mercury is also unsafe for the environment. Amalgams have long history of durability, less expensive and vastly used in the field of dentistry; there is still a debate on its use and disposal. Because of these concerns amalgam may have an uncertain future. Alternative materials like gold, gallium, composites etc. are successful filling materials now days but they also have some disadvantages like costs, durability issues etc. maybe this is the reason that amalgam fillings are still used by many countries. No matter which material is used, a filling is not natural tooth. There fillings are prepared by humans and are foreign particles for our body. As we all know foreign bodies are not accepted by our body and may show some side-effects in the form of allergic reactions or any diseases.

\section{REFERENCES}

[1] World Health Organization. Future use of material for dental restorations [Internet]. [cited 2015 Feb 12], http://www.who.int/oral_health/publications/dental_material_2011.pdf, 2011.

[2] World Health Organization. The World Oral Health Report 2003: Continuous Improvement of Oral Health in the 21st Century - the Approach of the WHO Global Oral Health Programme. Geneva: WHO, 2003.

[3] Bratthall D., Petersen P.E., Stjernswärd J.R. et al. , "Oral and craniofacial diseases and disorders", in Jamison D.T., Breman J.G., Measham A.R., et al., (eds), "Disease Control Piorities in Developing Countries. New York: World Bank Health and Oxford University Press", pp 723-736, 2006.

[4] Petersen P.E., Bourgeois D., Ogawa H. et al., "The Global Burden of Oral Diseases and Risks to Oral Health," Bull World Health Organ, Vol. 83 pp 661-669, 2005.

[5] Petersen P.E. Sociobehavioural risk factors in dental caries - international perspectives. Community Dent Oral Epidemiol. Vol. 33 pp. 274-279, 2005.

[6] Mackert Jr. J. R. and Wahl M. J., "Are there Acceptable Alternatives to Amalgam?" Journal of the California Dental Association, vol. 32, no. 7, pp. 601-610, 2004.

[7] Berthold M., "Restoratives: Trend Data Shows Shift in use of Materials" ADA News, vol. 33, pp. 10-11, 2002.

[8] American Dental Association Survey Center. The 1999 Survey of Dental Services Rendered, ADA Survey Center, Chicago, Ill, USA, 2002.

[9] Richardson G. M., Wilson R., Allard D., Purtill C., Douma S., and Gravi`ere J., "Mercury Exposure and Risks from Dental Amalgam in the US Population" post-2000, The Science of the Total Environment, vol. 409, no. 20, pp. 4257-4268, 2011.

[10] Brooks S.L., Rowe N.H., Drach J.C., Shipman C. Jr, and Young S.K., "Prevalence of Herpes Simplex Virus Disease in a Professional Population”, J Am Dent Assoc, vol. 102 pp-31-34, 1981.

[11] Prashant B., Firoza S., Jaiswal J.N., Bansal A., "Occupational Hazards among Dentists: A Review of Literature," Journal of International Medical and Dental Research, 4: 87-93, 2011.

[12] Bjorklund G., Mercury in the dental office, Risk Evaluation of the Occupational Environment in Dental Care, Tidsskr Nor Laegeforen. 111:948e51, 1991. [in Norwegian].

[13] Rowland A.S., Baird D.D., Weinberg C.R., Shore D.L., Shy C.M., Wilcox A.J., "The Effect of Occupational Exposure to Mercury Vapours on the Fertility of Female Dental Assistants", Occup Environ Med, Vol. 51 pp. 2834, 1994.

[14] Ngim C.H., Foo S.C., Boey K.W., Jeyaratnam J., "Chronic Neurobehavioral Effects of Elemental Mercury in Dentists" Br J Ind Med, Vol.49 pp.782e90, 1992

[15] Echeverria D., Heyer N.J., Martin M.D., Naleway C.A., Woods J.S., Bittner A.C., "Behavioural Effects of Low Levels Exposure to Hg0 among Dentists," Neurotoxicol Teratol, Vol.17 pp.161e8, 1995.

[16] Okabe T., "Mercury in the Structure of Dental Amalgam," Dental Materials, vol. 3, no. 1, pp. 1-8, 1987.

[17] Patterson J. E., Weissberg B. G., and Dennison P. J., "Mercury in Human Breath from Dental Amalgams," Bulletin of Environmental Contamination and Toxicology, vol. 34, no. 4, pp. 459-468, 1985.

[18] Vimy M. J. and Lorscheider F. L., "Serial Measurements of Intra-Oral Air Mercury: Estimation of Daily Dose from Dental Amalgam," Journal of Dental Research, vol. 64, no. 8, pp. 1072- 1075, 1985.

[19] Lorscheider F. L., Vimy J. M., and Summers A. O., "Mercury Exposure from "Silver" Tooth Firings: Emerging Evidence Questions a Traditional Dental Paradigm,” The FASEB Journal, vol. 9, no. 7, pp. 504-508, 1995.

[20] Anusavice K. J., 2003. Phillips' Science of Dental Materials, Saunders, Philadelphia, Pa, USA, 11 th edition.

[21] Dunn, J.E., Trachtenberg, F.L., Barregard, L., Bellinger, D., McKinlay, S., "Scalp Hair and Urine Mercury Content of Children in the Northeast United States: The New England Children's Amalgam Trial", Environmental Research, 107:79-88, 2008.

[22] Al-Saleh, I., Al-Sedairi, A., "Mercury (Hg) Burden in Children: The Impact of Dental Amalgam," Science of the Total Environment. 409:3003-3015, 2011.

[23] Zolfaghari, G., Esmaili-Sari, A., Ghasempouri, S.M., Faghihzadeh, S., "Evaluation of Environmental and Occupational Exposure to Mercury among Iranian Dentists,” Science of the Total Environment, 381:59-67, 2007.

[24] Geier D.A., Carmody T., Kern J.K., King P.G., and Geier M.R., "A Dose-dependent Relationship between Mercury Exposure from Dental Amalgams and Urinary Mercury Levels: a Further Assessment of the Casa Pia Children's Dental Amalgam Trial," Human and Experimental Toxicology, Vol. 31 no. 1 pp-11-17, 2012. 
[25] Balevi B., "Are Dental Amalgams Toxic to Children? Randomized Controlled Trials,” Debate Opinion, Vol. 73, No. 1. Pp. 51-54, 2007.

[26] Varkey I.M., Shetty R., Hegde A., "Mercury Exposure Levels in Children with Dental Amalgam Fillings," Int J Clin Pediatr Dent, Vol. 7 no. 3 pp-180-185, 2014.

[27] Rothwell J.A., and Boyd P.J., “Amalgam Dental Fillings and Hearing Loss” Int J Audiol, Vol. 47 no.12 pp-770-6, 2007.

[28] Mutter J., Yeter D., "Kawasaki’s Disease, Acrodynia, and Mercury” Curr Med Chem, Vol.15 no.28 pp- 3000-10, 2008.

[29] Moszczyński P., "Mercury and the Risk of Coronary Heart Disease" Przegl Lek, Vol.63 no. 7 pp- 64-7, 2006.

[30] Houston M.C., "The Role of Mercury and Cadmium Heavy Metals in Vascular Disease, Hypertension, Coronary Heart Disease, and Myocardial Infarction” Altern Ther Health Med, Vol.13 pp-128-133, 2007.

[31] Lindbohm M.L., Ylöstalo P., Sallmen M., "Occupational Exposure in Dentistry and Miscarriage," Occup Environ Med, Vol. 64 pp-127-133, 2007.

[32] Sheiner E.K., Sheiner E., Hammel R.D., Potashnik G., Carel R., "Effect of Occupational Exposures on Male Fertility: Literature Review," Ind Health. Vol. 4, pp-55-62, 2003.

[33] Mutter J., "Is Dental Amalgam Safe for Humans? The Opinion of the Scientific Committee of the European Commission," J Occup Med Toxicol, Vol. 6, no. 2, 2011.

[34] Hall R., Date: 08/12/2016. Amalgam Fillings and Mercury. https://evolvedental.com.au/amalgam-fillingsmercury/

[35] Opdam N.J., Bronkhurst E.M., Roeters J.M., Loomans B.A., “A Retrospective Clinical Study on Longevity of Posterior Composite and Amalgam Restorations" Dent Mater, Vol. 23, no.1 pp-2-8, 2009. http://www.ncbi.nlm.nih.gov/pubmed/16417916

[36] Mickenautsch S., Munshi I., \& Grossman E.S., Comparative cost of ART and conventional treatment within a dental school clinic, Journal of Minimum Intervention in Dentistry, 2009. http://www.miseeq.com/e-2-2-8.pdf.

[37] Mandari G.J., Frencken J.E., Van't Hof M.A., "Six-Year Success Rates of Occlusal Amalgam and Glass-Ionomer Restorations Placed Using Three Minimal Intervention Approaches,” Caries Res,Vol. 37 pp-246-253, 2003.

[38] Opdam N.J.M., Bronkhorst E.M., Loomans B.A.C., and Huysmana M.-C.D.N.J.M., "12-Year Survival of Composite vs. Amalgam Restorations,” Journal Of Dental Research ,Vol. 89, 10: pp. 1063-1067, 2010.

[39] Palkovicova L., "Maternal Amalgam Dental Fillings as the Source of Mercury Exposure in Developing Fetus and Newborn” J Expo Sci Environ Epidemiol, 2008. 